\title{
Prenatal Diagnosis and Postnatal Follow-up of Patients with Persistent Right Umbilical Vein
}

\author{
Daniel Beovide Leal, Magela Maggiolini, Ana Bianchi
}

\begin{abstract}
Objective: Through a prospective study the incidence and neonatal results of patients with persistent right umbilical vein are evaluated.
\end{abstract}

Materials and methods: During the period between August 2009 and February 2011, 3,576 low-risk obstetric sonographies were performed by the same technician at four different centers of prenatal diagnosis. Persistent right umbilical vein was diagnosed during a customary ultrasound examination, in the abdominal transverse section used to measure abdominal perimeter. Patients were asked to bring their children several months after delivery for a clinical and sonographic evaluation.

Results: Persistent right umbilical vein was found in nine fetuses. In one case, it was associated with single umbilical artery. All fetuses had good growth and development. In some children, the postnatal sonography showed the gallbladder toward the left of falciform ligament.

Conclusion: The incidence of persistent right umbilical vein in this population was of 1:397. We did not find any association with severe malformations as mentioned in the first articles related to this topic. There was only one case with single umbilical artery. All newborns developed normally. The question is raised why, being this anomaly so frequent and obvious, it is not more often diagnosed. Gallbladder position in respect to falciform ligament is a finding to assess.

Keywords: Right persistent umbilical vein, Fetal umbilical vascular system.

How to cite this article: Leal DB, Maggiolini M, Bianchi $A$. Prenatal Diagnosis and Postnatal Follow-up of Patients with Persistent Right Umbilical Vein. Donald School J Ultrasound Obstet Gynecol 2012;6(1):104-108.

\section{Source of support: Nil}

Conflict of interest: None declared

\section{INTRODUCTION}

Once a sonographic report mentions diagnosis of persistent right umbilical vein (PRUV) we inevitably have to first recapitulate embryology in order to understand the terminology, before we define this anomaly.

At fifth week of gestation three pairs of large-sized veins can be distinguished: (1) The omphalomesenteric veins which develop as a venous network below the heart and parallel to the umbilical veins, transporting blood via the vitelline veins from yolk sac to sinus venosus, (2) the umbilical veins which bring the nutrient- and oxygen-rich blood from the placental villi via the umbilical cord to the embryo and (3) common cardinal veins as confluence of two superior cardinal veins which bring the blood from the head region, and two inferior cardinal veins which drain the blood from the lower half of the body into the two common cardinal veins. ${ }^{1}$

Consequently at this stage of embryonic life there is a right umbilical vein as well as a left umbilical vein, both passing either sides of the liver through the splanchnic mesoderm, and opening into the horns of the sinus venosus. Soon after connecting to the hepatic sinusoids and capillary plexus of the liver, first the proximal parahepatic portion of both umbilical veins disappears (Carnegie stage 15, day 32), followed by obliteration of the rest of the right umbilical vein (Carnegie stage 20, day 49). At around 7 weeks, the right umbilical vein has vanished. As a result, the left umbilical vein becomes the only vessel to transport the blood from the placenta to the liver.

The obliteration of the left instead of the right umbilical vein does not prevent the formation of the ductus venosus. Hence, in spite of a left-right inverted flow of blood within the liver, the distribution of blood to the fetus remains equal.

Persistence of right umbilical vein (PRUV) is defined as an anatomic vascular variant visible in the transversal abdominal plane: The abdominal section of the umbilical vein (UV) curves toward the gastric chamber and not toward the liver as normally. Moreover, the gallbladder can be observed between the umbilical vein and the stomach instead right lateral of the $\mathrm{UV}{ }^{2}$

The first published studies presented PRUV as a rare entity associated with severe anomalies including cardiac, gastrointestinal, urinary and musculoskeletal defects. ${ }^{3}$

Later studies, seeking the diagnosis in low-risk patients, have given a higher frequency of occurrence with favorable prognosis. ${ }^{4}$

In our country, Uruguay, PRUV is seldom or not at all mentioned although diagnosis is very simple and done simultaneously with the customary examination of abdominal perimeter.

The purpose of this study is to investigate the approximated incidence in our environment as well as associations with other malformations and anatomic variants, diagnosis of or clinic impairments during postnatal development. 


\section{MATERIALS AND METHODS}

The prospective study was conducted in four different medical centers (Asse, Aepsm, Mucam and Pereira Rossell Hospital $)^{5}$ where technicians used different types of equipment, such as, Esaote 30, Toshiba Xario and Medison Accuvix respectively.

Obstetric ultrasound examinations were performed from August 2009 until February 2011 in low-risk patients, paying special attention to the curve of the portal vein as well as to the position of the gallbladder when measuring the abdominal perimeter.

First trimester sonographies were excluded due to impossibility of diagnosis at this early stage of pregnancy.

Studies were carried out by only one technician. Once PRUV was suspected, a new way of evaluation was performed by the chief of the service (Ana Bianchi, MD) in order to confirm the diagnosis. Moreover, a detailed scan to detect associated prenatal malformations followed.

A fetal echocardiography was suggested in all cases.

The patients were asked to give their telephone numbers, addresses, as well as their agreement to be called in for an appointment after their child's birth, in order to get the necessary information about the clinical development of the child, and to facilitate a free-of-charge postnatal sonographic follow-up.

Parents were requested to bring their babies months later for completion of a perinatal questionnaire with data of postnatal development. This also included a sonographic evaluation of the baby's abdomen by an ultrasound technician specialized in pediatric echography (Magela Maggiolini, MD).

\section{RESULTS}

A total of 3576 echographies of the second and third trimester were done during 21 months from August 2009 and February 2011, at four centers of prenatal diagnosis in Montevideo (MUCAM 1672, 46\%, ASSE 903, 25\%,
AEPSM 798, 22\%, HPR 203, 6\%). Nine patients with PRUV were found, thus the incidence was of one in 397.

The average maternal age was 29 years with a maximum of 39 years and a minimum of 16 years. Seven patients denied giving information about their background. One of them was a smoker during the first trimester of pregnancy, and the other was suffering from asthma. At the moment of diagnosis five patients were primiparae, three were multiparous with four and five previous deliveries. There was one secundipara.

In eight of the patients, PRUV was diagnosed during the third trimester, once only during the second trimester. In six of the patients the diagnosis was made in July, August and September, and in three of them during February and March.

Five of the nine patients received a supplement of folic acid during pregnancy. A fetal echocardiography was performed in seven of the nine patients. The other two were difficult to coordinate due to their advanced pregnancies.

The ductus venosus could be located, and was intrahepatic in all patients.

All mothers denied having any pathology during the first trimester of pregnancy. During the second trimester, two of them suffered threats of preterm delivery. One-half of the patients had cesarean sections, the other half normal deliveries. All patients had full term deliveries. None had babies with low birth weight. The average weight was $3391 \mathrm{gm}$. All babies had good growth and development (Table 1).

Patients were asked for their telephone numbers, enabling us to have contact with seven of them, months after births. Two of them were not located, one had moved and deleted her telephone book entry. The other one had given false telephone number. We had however, evidence from the medical records of both patients, that growth and development of the babies during lactation was normal.

Four of nine mothers brought their children for abdominal ultrasonography which was performed by Magela Maggliollini, MD. From the five absent patients,

\begin{tabular}{|c|c|c|c|c|c|c|c|c|c|}
\hline S. No. & Age & Obst. rec & Pers.rec & Pat 1 trim & $\begin{array}{l}\text { Gest. age } \\
\text { of diag }\end{array}$ & $\begin{array}{l}\text { Echo- } \\
\text { cardio }\end{array}$ & $\begin{array}{l}\text { Deliv. or } \\
\text { C-section }\end{array}$ & Weeks & $\begin{array}{l}\text { Weight } \\
\text { (in gm) }\end{array}$ \\
\hline 1 & 39 & 4 gest. 4 deliveries & Smoker & None & 39 & No & Delivery & 41 & 3350 \\
\hline 2 & 32 & $\begin{array}{l}4 \text { gest. } 3 \text { deliv. } \\
1 \text { C-section }\end{array}$ & Asthmatic & None & 30 & Yes & Delivery & 39 & 3540 \\
\hline 3 & 28 & 0 gestation & None & None & 29 & Yes & C-section & 38 & 2790 \\
\hline 4 & 18 & 0 gestation & None & None & 32 & Yes & C-section & 40 & 3830 \\
\hline 5 & 24 & 1 gest. 1 delivery & None & None & 22 & Yes & Delivery & 40 & 3220 \\
\hline 6 & 16 & 0 gestation & None & None & 29 & Yes & & & 3600 \\
\hline 7 & 34 & 0 gestation & None & None & 37 & Yes & C-section & 41 & 3880 \\
\hline 8 & 32 & 0 gestation & None & None & 37 & No & C-section & 39 & \\
\hline 9 & 34 & 5 gest. 5 deliveries & None & None & 33 & Yes & Delivery & 39 & 2920 \\
\hline
\end{tabular}


two could not be contacted by telephone, and three of them had telephone interviews to collect all necessary clinical data.

\section{DISCUSSION}

From the first study reported by Jeanty ${ }^{3}$ in 1995 until now, many studies have revalued the incidence of PRUV.

Among them, I Wolman evaluated a total of 8950 patients between 1995 and 1998. Seventeen patients were diagnosed PRUV, with an incidence of 1:526.

Hill et $\mathrm{al}^{6}$ observed PRUV in 33 patients of a total of 15237 consecutive obstetric sonographies, with an incidence of 1:476. One of the most extended studies was conducted by Blazer et $\mathrm{al}^{7}$ who, during a period of 10 years (19901999), examined 30, 240 pregnant women and diagnosed in 69 of them persistence of right umbilical vein, marking an incidence of 1:438.

In the present study we found an incidence of 1:397, which shows that in our environment PRUV is also a frequent diagnosis.

Why is this diagnosis not made more frequently? Because we do not look for it and succumb to the diagnostic deadlock 'we know what we look for, and we look for what we know' or do we eventually not consider these findings to be important?

The diagnosis is 'hidden' in the same section and plane in which physicians usually perform measurements of the abdominal perimeter. This means that making the diagnosis is always possible, in an examination during the second and third trimester. Or are the standard rules for measurement of the abdominal perimeter not applied?

The abdominal perimeter is measured in a plane which enables to appreciate the size of the liver. The liver is the biggest fetal organ and its size reflects growth alterations. Thus, fetal abdominal circumference ratio is not measured at navel level but where the transverse diameter of the liver is the highest. This can be determined by scanning in the plane where right and left portal veins join, forming the 'hockey stick'. Then, the appearance of ribs must be symmetric. Finally, we need to scan in the plane of the shortest length of the umbilical segment of the left portal and the gastric vein. ${ }^{8}$

Whenever, measuring the abdominal perimeter, physicians are able to look for the 'hockey stick'. A persistent right umbilical vein is oriented toward the stomach and not toward the right lobe of the liver. The fetal gallbladder will be seen between the umbilical portion of the left portal vein and the stomach, i.e. the gallbladder is positioned medial to the PRUV, confirming the diagnosis (Figs 1 to 3 ).

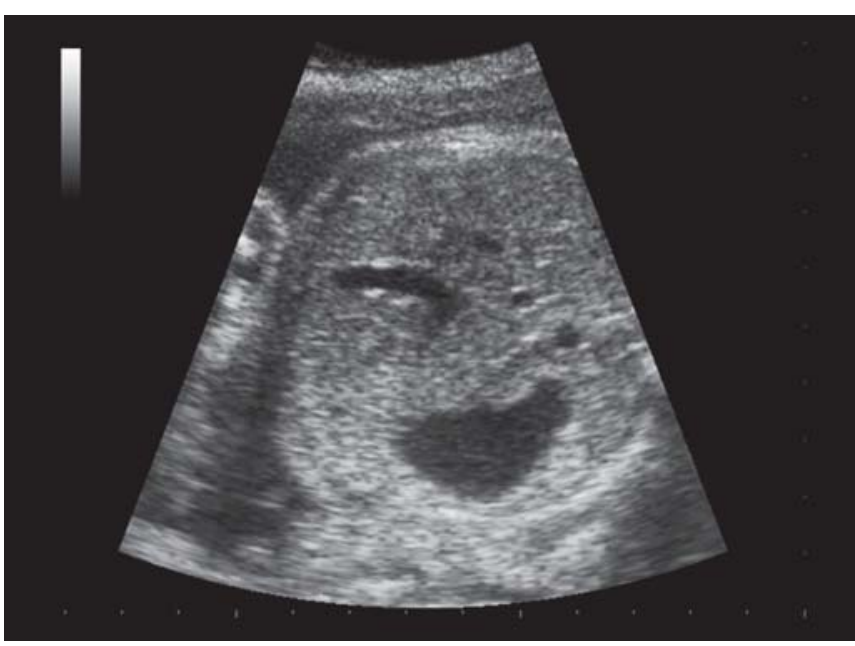

Fig. 1: Abdominal transversal section visualizing ribs, spinal column, gastric chamber, aorta, inferior vena cava, and umbilical portion of portal vein curving toward the left instead of the right

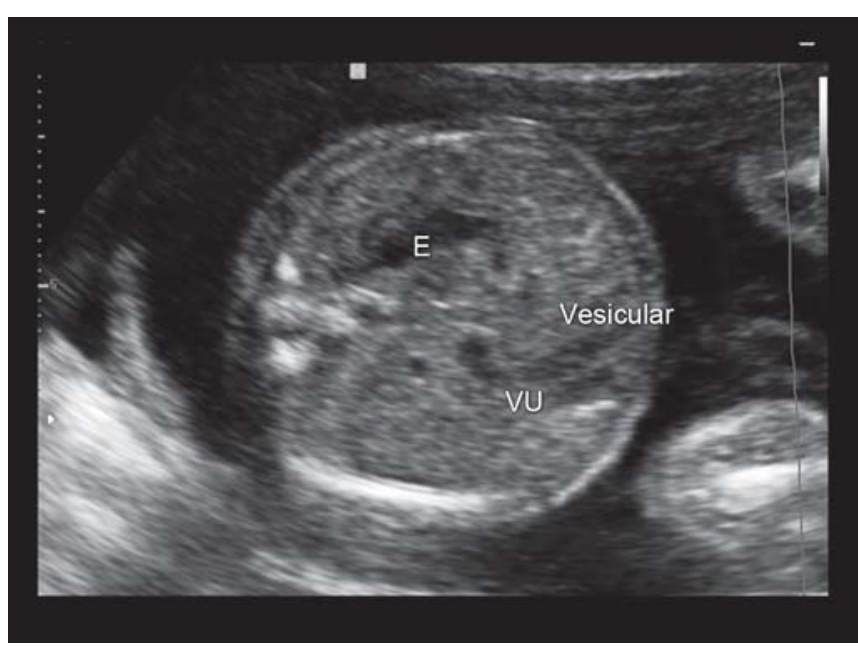

Fig. 2: Gallbladder is visualized between umbilical portion of portal vein (PV) and the stomach

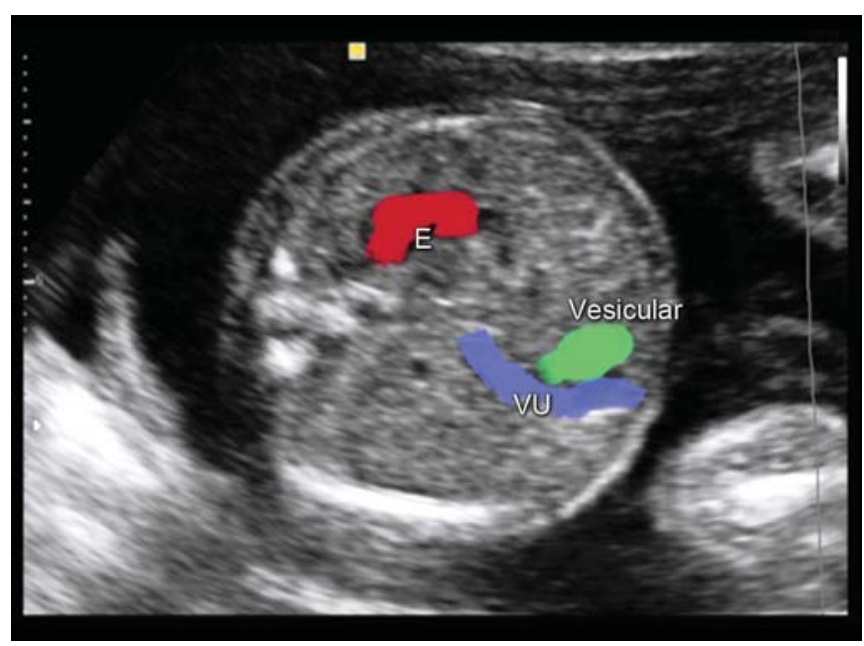

Fig. 3: Idem figure 2 but with color marks

The right umbilical vein can be intrahepatic, ending in the portal vein or extrahepatic, presenting an anomalous ending for instance directly connected to right auricula, 


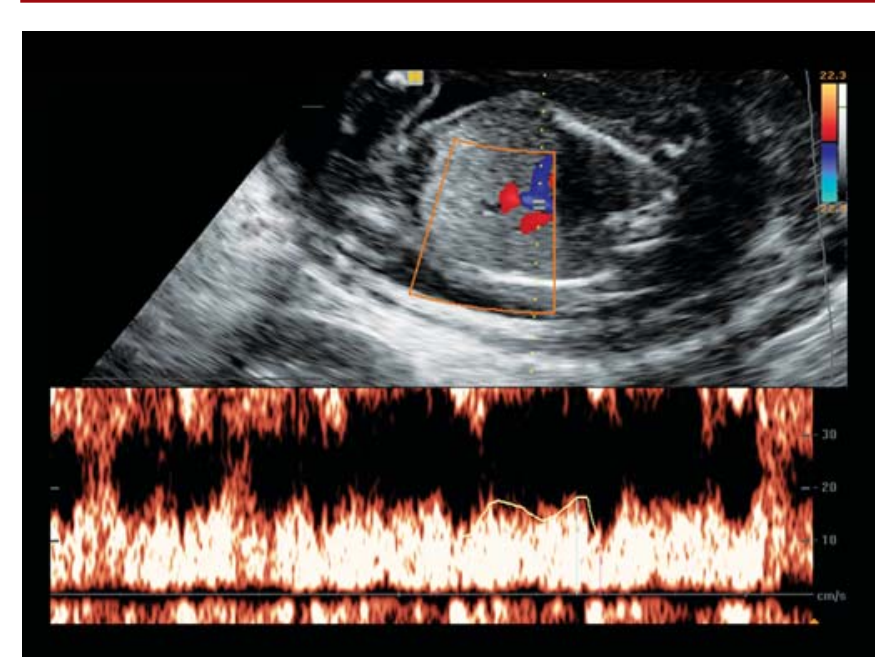

Fig. 4: Right parasagittal section aiming to visualize ductus venosus. A necessary second step after performing the diagnosis with the objective to know the variety (intrahepatic or extrahepatic)

inferior vena cava, below the liver or to superior vena cava. The most severe associations which include cardiovascular malformations as well as other systemic malformations are generally produced in association with extrahepatic variety. ${ }^{9}$

For this reason it is important to visualize the ductus venosus by means of color Doppler (Fig. 4).

In all nine patients with PRUV, ductus venosus was evaluated and always intrahepatic, without anomalous connection. The conclusion was that all of them were intrahepatic variants.

In respect to association of PRUV with other malformations, the single umbilical artery (SUA) is the most frequent one, and was the only association found in our study.

Malformations of cardiac, renal, central nervous system and other organs as associated in early literature with PRUV were not found in our study, although they were specifically searched for in a second ultrasound study.

A fetal echocardiogram was always suggested. In the majority of cases, it could be performed prenatally without finding any associated cardiopathies.

The reason to perform a postnatal abdominal echography was to visualize the falciform ligament which is the remnant of the ventral mesentery, the most ventral section of the septum transversum (ST). The ST connects spleen, stomach and liver. The big question is if PRUV produces a visible anatomic change in ultrasound, especially vascular and/or topical changes of the gallbladder, which in a prenatal stage can be seen left of umbilical vein, whereas the normal location is right of it (Fig. 5).

In case of alterations: Do they cause any clinical pathology? Or can it be useful to know that they exist?

The falciform ligament could be located in $100 \%$ of cases during the four postnatal abdominal sonographies.

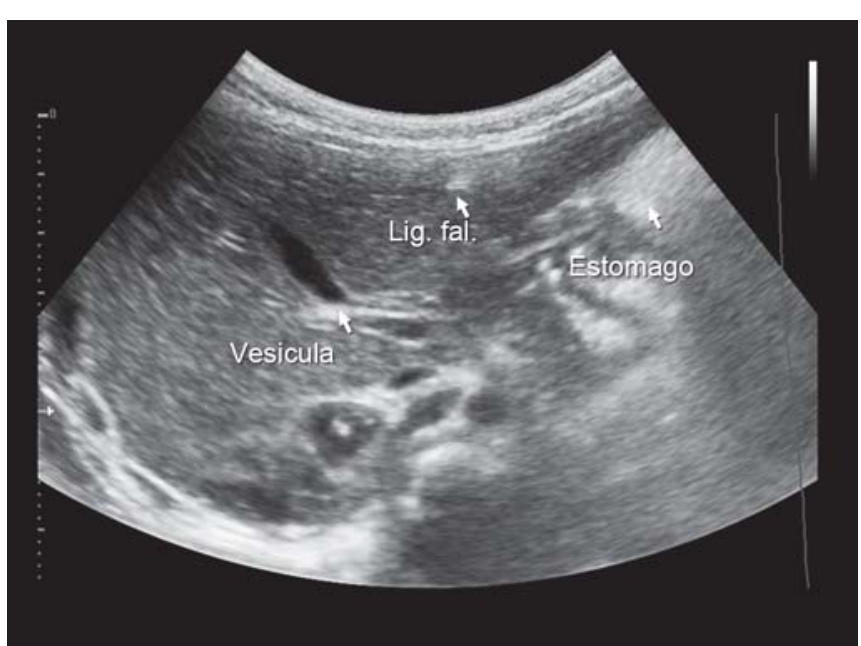

Fig. 5: Transversal abdominal section performed after birth at hepatic level where gallbladder can be seen toward the right of falciform ligament (fal. lig.) or round ligament (remnant of umbilical vein) and the stomach toward the left

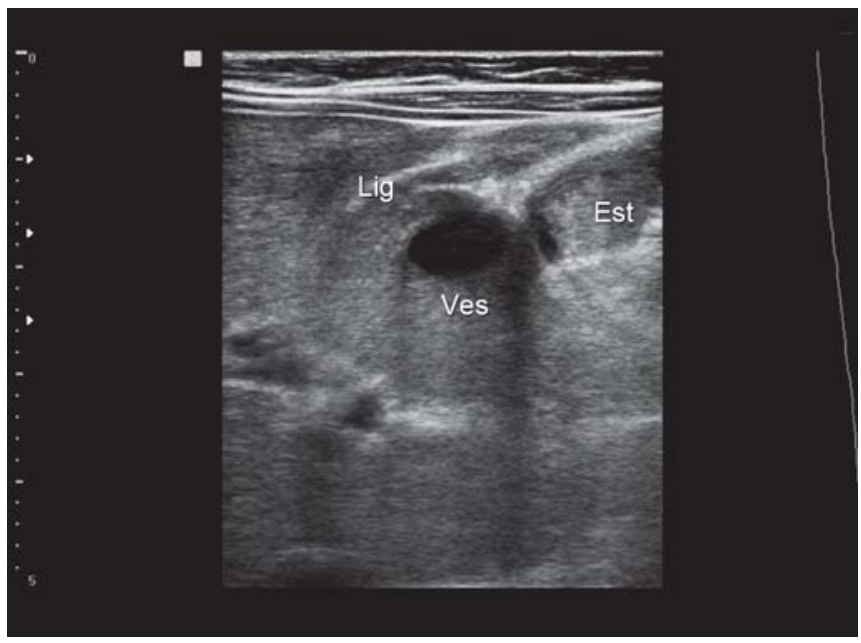

Fig. 6: Transversal abdominal section, after birth, at hepatic level where gallbladder (GB) is seen toward the left of falciform ligament (LIG) and toward the right of stomach (ST)

It was confirmed in two cases, that the gallbladder was located left of the ligament (Fig. 6). In the other two, it was located on the right.

This may be data worth to be revised in long-term follow-up of patients. Eventually, this can be taken into account, when a gallbladder or liver surgery is necessary.

\section{CONCLUSION}

With the authors of other published studies, we share the opinion that PRUV is a frequent finding.

The sonographic diagnosis can be made following the rules for customary abdominal perimeter evaluation. This means, if PRUV is present, it is a simple diagnosis.

The intrahepatic variation is the most common one and has low association with other malformations.

The single umbilical artery is the most frequent associated finding as mentioned by other studies as well. 
The prognosis is favorable, in our study in $100 \%$ of cases, but this is just a small sample.

After diagnosis it is recommended to look for the intraor extrahepatic anomaly, by confirming ductus venosus location.

A detailed sonography and fetal echocardiography are required to look for association with other malformations.

It is suggested to perform a postnatal abdominal sonography to look for gallbladder location on the right or the left of falciform ligament.

Demonstration of the gallbladder location in relation to the falciform ligament, and evaluation of its clinical correlation, ${ }^{10}$ will be the objective of a future study after follow-up of these patients, as well as in those future cases to be found from February 2011 onward. The future study may also validate options of 3D ultrasound with power Doppler for better delineation of local anatomy, as described by several authors. ${ }^{11-16}$

\section{REFERENCES}

1. Langman. Medical embryology (4th ed). 1981;196-97.

2. Eghon Guzman. Ultrasonography and obstetrics, selected topics. 286-87.

3. Jeanty P. Persistent right umbilical vein: An ominous prenatal finding? Radiology 1990;177:735-38.

4. Wolman I. Persistent right umbilical vein: Incidence and significance. Ultrasound Obstet Gynecol 2002;19:562-64.

5. Asse: Administración de los Servicios de Salud del Estado, Aepsm: Asociación Española Primera de Socorros Mutuos, Mucam: Medica Uruguaya. HPR: Pereira Rossell Hospital.

6. Hill LM, Mills A, Peterson C, Boyles D. Persistent right umbilical vein: Sonographic detection and subsequent neonatal outcome. Ultrasound Obstet Gynecol 1996;8:31-33.

7. Blazer persistent intrahepatic right umbilical vein in the fetus: A benign anatomic variant. Obstetrics and Gynecology, 2000;3:433-36

8. Callen. Ecography in obstetrics and gynecology (4th ed). 153.

9. Cafici. Doppler ultrasonography in obstetrics. 303-04.

10. Weichert J, Hartge D, Germer U, Axt-Fliedner R, Gembruch U. Persistent right umbilical vein: A prenatal condition worth mentioning? Ultrasound in Obstetrics and Gynecology May 2011;37(5):543-48.

11. Yang PY, Wu JL, Yeh GP, Chou PH, Hsu JC, Hsieh C TC. Prenatal diagnosis of persistent right umbilical vein using threedimensional sonography with power doppler. Taiwanese Journal of Obstetrics and Gynecology August 2004;46(1): 43-46.

12. Sciaky-Tamir Y, Cohen SM, Hochner-Celnikier D, Valsky DV, Messing B, Yagel S. Three-dimensional power Doppler (3DPD) ultrasound in the diagnosis and follow-up of fetal vascular anomalies. American Journal of Obstetrics and Gynecology January 2006;194(1):274-81.

13. Kalache K, Romero R, Goncalves LF, Chaiworapongsa T, Espinoza J Schoen ML, Treadwell MC, Lee W. Threedimensional color power imaging of the fetal hepatic circulation. American Journal of Obstetrics and Gynecology November 2003;189(5):1401-06.

14. Gindes L, Pretorius DH, Romine LE, Kfir M, D’Agostini D, Hull A, Achiron R. Three-dimensional ultrasonographic depiction of fetal abdominal blood vessels. JUM 1 August, 2009;28(8):977-88.

15. Sciaky-Tamir Y, Cohen SM, Hochner-Celnikier D, Valsky DV, Messing B, Yagel S. Three-dimensional power Doppler (3DPD) ultrasound in the diagnosis and follow-up of fetal vascular anomalies. Am J Obstet Gynecol 2006;194:274.

16. Kurjak A, Miskovic B, Andonotopo W, Stanojevic M, Azumendi G, Vrcic H. How useful is 3D and 4D ultrasound in perinatal medicine? J Perinat Med 2007;35:10-27.

\section{ABOUT THE AUTHORS}

\section{Daniel Beovide Leal}

Specialist, Department of Obstetrics and Gynecology, Hospital Pereira Rossell, Montevideo, Uruguay

\section{Magela Maggiolini}

Pediatrician Radiologist, Department of Obstetrics and Gynecology Hospital Pereira Rossell, Montevideo, Uruguay

\section{Ana Bianchi (Corresponding Author)}

Director, Department of Fetal Medicine, Hospital Pereira Rossell Montevideo, Uruguay 